\title{
大别山北淮阳带西段新元古代浅变质花岗岩的发现 及其大地构造意义
}

\author{
刘贻灿 ${ }^{(1)}$, 刘理湘 ${ }^{(1)}$, 古晓锋 ${ }^{(1)}$, 李曙光 ${ }^{(1)}$, 刘佳 ${ }^{(1)}$, 宋彪 ${ }^{(2)}$ \\ (1) 中国科学院壳幔物质与环境重点实验室，中国科学技术大学地球和空间科学学院，合肥 230026; \\ (2) 北京离子探针中心, 北京 100037 \\ E-mail: liuyc@ustc.edu.cn \\ 2010-03-15 收稿, 2010-07-05 接受 \\ 国家重点基础研究发展计划(2009CB825002)和国家自然科学基金(40921002, 40973043, 40634023, 90814008)资助项目
}

\begin{abstract}
摘要 经过详细的野外地质调查和室内薄片观察，在大别山北淮阳带西段原“定远组”变质 火山岩中发现新元古代侵位的浅变质花岗岩。对其中两个浅变质花岗岩样品进行了锆石 SHRIMP U-Pb 定年和初步的岩石学研究. 结果表明, 这些浅变质花岗岩经过了强烈的构造 变形和绿穷角闪岩相变质作用, 它们的形成时代分别为 $(726 \pm 6)$ 和 $(758 \pm 12) \mathrm{Ma}$, 并且与北 淮阳带东段庐镇关杂岩的形成时代一致. 结合前期发现的(635 5 ) Ma 浅变质(橄榄)辉长岩, 证明北淮阳带至少存在两类新元古代侵入岩, 即 726 758 Ma 的变质花岗岩和 $635 \mathrm{Ma}$ 的变 质辉长岩. 这些新元古代岩石出露于变质的奥陶纪岩火山岩带(原“定远组”)中，二者之间 为构造接触以及分别形成于不同的大地构造背景, 并且它们与华南陆块北缘湖北随州-束 阳一带发育的二期大规模新元古代中、晚期基性岩墙群和花岗岩的时代以及大别山超高压 岩石的原岩时代一致. 这进一步证明, 它们可能是印支期华南陆块发生俯冲的初始阶段最 早被拆离、解耦的岩片, 并在南、北陆块汇聚、碰撞及造山过程中被推覆到华北陆块南缘 古生代浅变质岩系之上.
\end{abstract}

\section{关键词}

浅变质花岗岩

新元古代

SHRIMP U-Pb 定年

大陆俯冲

北淮阳带西段
新元古代, 特别是新元古代中、晚期, 是地质历 史上一个重要时期：一方面是因为发育两期全球性 冰期事件(即 720 670 Ma 的 Sturtian 冰期和 650 635 $\mathrm{Ma}$ 的 Marinoan 冰期)和两期局部大陆冰川事件(即 750 780 Ma 的 Kaigas 冰期和 575 585 Ma 的 Gaskiers 冰期 $)^{[1-8]}$; 另一方面是发生了全球性的大规模岩浆 活动, 并被认为与 Rodinia 超大陆的裂解有关 ${ }^{[2,6,9 ~ 11]}$. 而且，地层证据表明，冰期事件的开始和结束时间都 是突然发生的 ${ }^{[6,7,11,12]}$. 因此, 冰期的结束也许是与 Rodinia 超大陆裂解造成的大规模岩浆活动有关 ${ }^{[11,12]}$.

众所周知, 华南陆块, 特别是华南陆块北缘, 在 新元古代发生过多期、标志性的大规模岩浆活 动 ${ }^{[10,11,13 \sim 19]}$. 而大别-苏鲁超高压变质岩的原岩时代
一般为 620 820 $\mathrm{Ma}^{[16]}$, 并且年龄主要集中在 750 和 $780 \mathrm{Ma}^{[11]}$, 是华南陆块北缘存在新元古代中期大规 模裂谷岩浆活动的标志, 是对 Rodinia 超大陆裂解事 件的响应, 也与古城(Kaigas) 冰期的开始时间 ${ }^{\left[{ }^{[} \text {相吻 }\right.}$ 合. 此外, 在华南陆块的陡山沱组的底部沉积岩中普 遍发育 $635 \mathrm{Ma}$ 左右的火山凝灰岩夹层，而 $635 \mathrm{Ma}$ 对 应于南沱 (Marinoan) 冰期的结束时间 ${ }^{[3 \sim 5]}$. 近期研 究 ${ }^{[20]}$ 还发现, 北淮阳带西段(商城-麻城断裂以西)原 “定远组”变质火山岩中发育大量新元古代晚期 635 $\mathrm{Ma}$ 浅变质基性岩, 并与湖北随州-束阳一带发育的一 期大规模新元古代晚期基性岩墙群的时代一致.

近年来，大别山东段(商城-麻城或商-麻断裂以 东)及苏鲁造山带中陆续发现一些浅变质的新元古代 
岩石, 如大别山超高压带中港河绿片岩相岩石 ${ }^{[21,22] 、}$ 北淮阳带东段庐镇关杂岩中花岗片麻岩和斜长角闪 岩 ${ }^{[23 ~ 30]}$ 以及苏鲁地区五莲花岗片麻岩 ${ }^{[31]}$ 等, 属于华 南陆块北缘的一部分. 它们以低绿片岩相-绿帘角闪 岩相变质作用为主. 庐镇关杂岩中花岗片麻岩的角 闪石 $\mathrm{Ar}-\mathrm{Ar}$ 年龄 ${ }^{[23]}$ 与锆石 $\mathrm{U}-\mathrm{Pb}$ 年龄 ${ }^{[26,29,30]}$ 一致 $(\sim 750$ $\mathrm{Ma})$ ，仍能记录其原岩年龄而未被后期变质作用干扰; 但其中白云母的 $\mathrm{Ar}-\mathrm{Ar}$ 年龄为 $(241.9 \pm 2.3) \mathrm{Ma}^{[23]}$, 记 录了与三叠纪大陆碰撞相关的变质时代. 这表明这 些杂岩在新元古代以后的变质反应温度都低于角闪 石的 $\mathrm{Ar}-\mathrm{Ar}$ 封闭温度 $\left(\sim 500^{\circ} \mathrm{C}\right)$ 而高于白云母的 $\mathrm{Ar}-\mathrm{Ar}$ 封闭温度 $\left(\sim 350^{\circ} \mathrm{C}\right)$. 但是, Tang 等人 ${ }^{[32]}$ 通过对胶北地 块南缘粉子山群大理岩中的锆石进行 SHRIMP U-Pb 定年, 发现其原岩时代为 $(786 \pm 67) \mathrm{Ma}$, 变质时代为 $(240 \pm 44) \mathrm{Ma}$, 由此认为该大理岩原岩形成于华南陆 块北缘并参与了印支期大陆碰撞. 因此, 可以认为它 们都是陆壳俯冲初始阶段被拆离、刮下来的“加积 楔”, $222,24,28,33]$.

上述两种新元古代浅变质岩片的研究成果证明, 大别-苏鲁俯冲陆壳在发生榴辉岩相变质前有可能在 浅部不同深度发生了地壳的拆离 ${ }^{[20,28,33]}$. 查明这些浅 变质岩片在造山带的分布范围对认识陆壳俯冲初期 的拆离、解耦及其就位机制有重要意义. 商-麻断裂 以西的北淮阳带西段是大别山造山带的重要组成部 分, 而且发育三叠纪华南陆壳俯冲前的古生代岩浆 弧 ${ }^{[34,35]}$ 等浅变质岩石单位, 因而是研究大别山大陆 俯冲前演化历史的最佳地区. 其中, 查明该区陆壳深 俯冲初期最早被解耦的浅变质岩片的岩石组成, 特 别是查明是否存在类似于北淮阳带东段庐镇关杂岩 中新元古代中期(740 780 Ma)的变质花岗岩和变基 性岩等, 具有重要的科学意义.

\section{1 地质背景}

秦岭-大别-苏鲁造山带是位于中国中部华南与 华北两个大陆板块之间的一条碰撞型造山带, 也是 近 20 年来国际上大陆动力学研究的热点地区. 大别 山位于该带的中段, 从南到北, 大致可划分为宿松变 质带、南大别(红安)低温榴辉岩带、中大别超高压变 质带、北大别杂岩带及北淮阳带等构造岩石单 位 ${ }^{[17,18,28,33,36 ~ 39]}$. 其中, 榴辉岩相高压-超高压变质岩
石仅发现于桐柏-桐城断裂或磨子潭-晓天断裂以南, 该断裂以北称为北淮阳带. 但是, 近年来发现北淮阳 带东段庐镇关杂岩(原庐镇关群)中花岗片麻岩或变 质花岗岩以及(含石榴)斜长角闪岩的形成时代为 720 780 $\mathrm{Ma}^{[6,10,11,25 ~ 27,29,30]}$, 证明华南板块与华北板 块之间在三叠纪大陆碰撞过程中的缝合线位置处于 北淮阳低级变质带之下或北缘，而不是处于高压-超 高压变质带北缘的晓天一磨子潭断裂 ${ }^{[28]}$.

北淮阳带西段(商-麻断裂以西)主要由浅变质的 原信阳群南湾组(变质复理石)和龟山组(又称龟山杂 岩)、原苏家河群的定远组和原石炭纪梅山群等岩石 单位以及新元古代浅变质基性岩、古生代闪长岩等花 岗岩类岩石和中生代岩石等组成(图 1). 其中, 新元 古代浅变质(橄榄)辉长岩沿桐柏-桐城断裂(研究区为 定远-苏家河-八里畈断裂，东段为磨子潭-晓天断裂) 的北侧, 从千斤河棚乡王母观向西经苏家河至信阳 南部西双河和桐柏一带呈大小不等的岩块或岩片出 露, 千斤河棚乡向东经吴陈河乡至八里畈乡一带也 有类似岩石断续分布. 其围岩为原“定远组”变质火 山岩, 目前表现为含石榴子石绿帘云母石英片岩. 二 者之间为构造接触 ${ }^{[20]}$. 该区变质火山岩属于原 $1: 200000$ 新县幅区调建立的苏家河群定远组的一部 分, 但河南省地质矿产勘查开发局第三地质调查队 在 1:50000 地质图上将其划归震旦系-下奥陶统肖家 庙岩组 ${ }^{1}$. 其南、北分别与湤湾榴辉岩带和“南湾组”变 质复理石等构造岩石单位相邻，再向南为新县超高 压变质带, 见图 1. 因原苏家河群湤湾组中榴辉岩既 有石炭纪洋壳俯冲成因榴辉岩(如熊店) ${ }^{[34,40 \sim 45]}$, 也有 三叠纪陆壳俯冲成因榴辉岩 ${ }^{[34,40,41]}$, 它们的原岩时代 分别为古生代 ${ }^{[34,40,44]}$ 和新元古代 ${ }^{[40,41]}$, 因而称之为吘 湾混杂岩带 ${ }^{[20,34,40,46]}$, 它的变质相及形成时代完全不 同于 “定远组”即表现为绿帘角闪岩相和形成时代为 奥陶纪 $[34,40,41,46]$.

到目前为止, 北淮阳带西段未曾报道过浅变质 花岗岩. 经详细野外地质调查和室内薄片观察, 我 们在原“定远组”变质火山岩中发现浅变质花岗岩. 为此, 本文对其中两个浅变质花岗岩样品进行了 岩石学和锆石 SHRIMP U-Pb 定年研究并报道初步 结果.

1) 河南省地质矿产勘查开发局第三地质调查队, 1:50000 千斤河棚幅地质图及说明书, 2001 


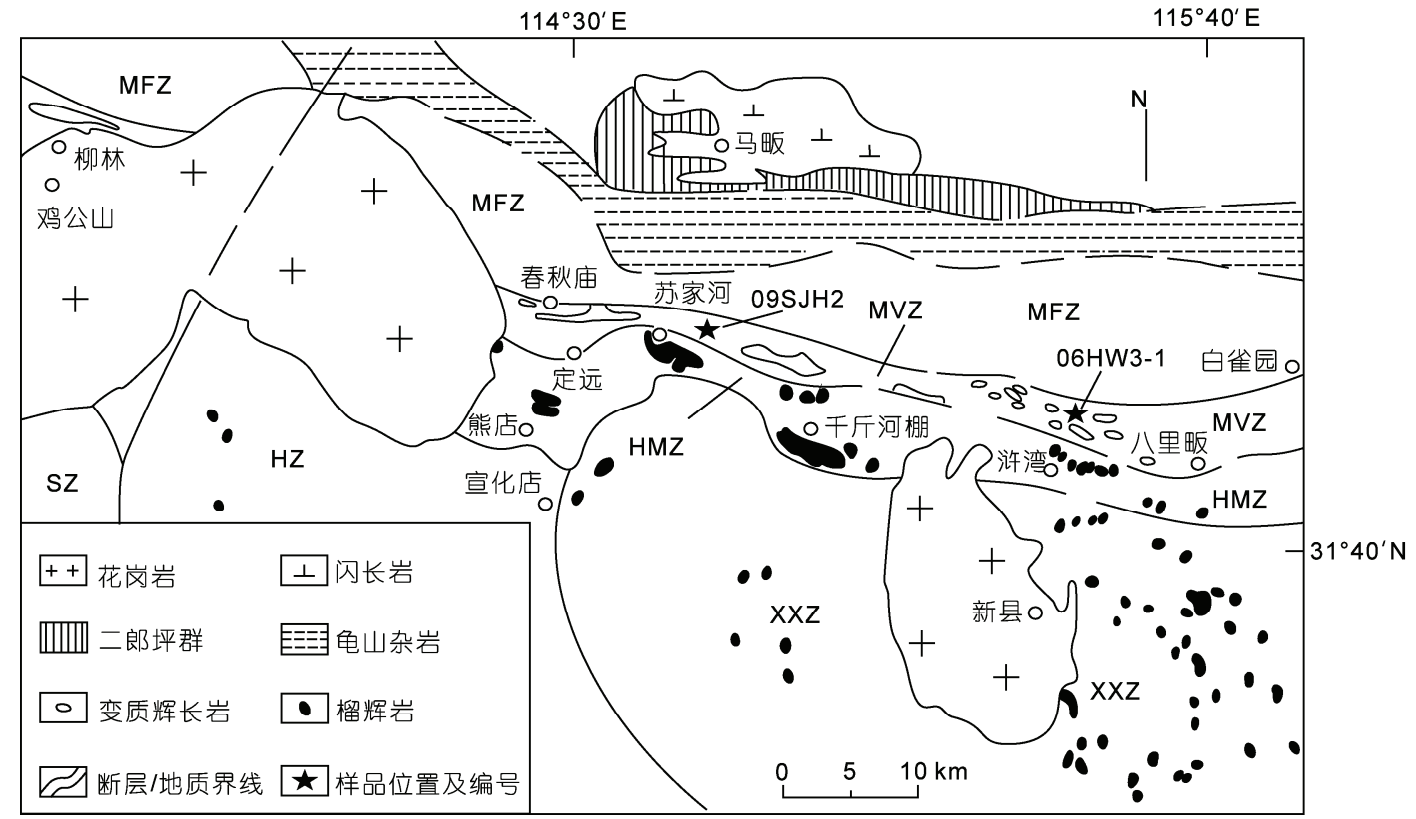

图 1 北淮阳带西段的地质简图

MFZ 为“南湾组”变质复理石带, MVZ 为“定远组”变质火山岩带, HMZ 为湤湾混杂岩带, XXZ 为新县超高压变质带, HZ 为红安低温榴辉岩带, $\mathrm{SZ}$ 为宿松变质带

\section{2 样品描述及分析方法}

本样品采集自苏家河以东和湤湾以北的公路旁 采石场(图 1,2). 所分析样品为变质花岗岩(样号为 09SJH2 和 06HW3-1). 09SJH2 样品的主要矿物为钾长 石 $(30 \% \sim 40 \%)$ 、斜长石 $(20 \% \sim 30 \%)$ 、石英 $(25 \%)$ 、白 云母 $(5 \% \sim 10 \%)$ 、石榴子石 $(<5 \%)$ 、角闪石 $(<5 \%)$ 和绿 帘石(3\%)等(图 3(a) (d)); 06HW3-1 样品的主要矿物 有斜长石 $(30 \% \sim 40 \%)$ 、钾长石 $(20 \% \sim 30 \%)$ 、石英 $(20 \% \sim 25 \%)$ 、绿帘石 $(<5 \%)$ 、榍石 $(2 \%)$ 和角闪石 $(3 \%)$ 等(图 3(e) (f)), 次要矿物有磁铁矿、磷灰石等. 两个 样品都已发生强烈变形, 表现为强烈面理化以及部 分矿物的细粒化、重结晶和定向排列等即已糜棱岩化 和局部已达到糜棱岩, 并经历了低级变质作用(图 2, 3). 其中, 变质形成的绿帘石和角闪石等矿物大致沿 面理分布(图 3), 表现为绿帘角闪岩相.

将上述两个样品的锆石和标准锆石 TEMORA (年龄为 $417 \mathrm{Ma}$ )一起制成样品靶 ${ }^{[47]}$, 抛光后将待测 锆石进行透射光、反射光和阴极发光 (CL) 显微照相. 阴极发光照相在北京离子探针中心完成. 锆石微区 $\mathrm{U}-\mathrm{Pb}$ 定年测试在中国地质科学院北京离子探针中 心 SHRIMP II 离子探针仪器上进行, 详细测定程序 见文献[47 49]. 测试时所用的标准锆石为 SL13 和
TEMORA，前者用于标定 $U$ 和 $\mathrm{Th}$ 的含量，后者用于 校正年龄. 束斑直径约为 $20 \mu \mathrm{m}$. 测定结果用实测 的 ${ }^{204} \mathrm{~Pb}$ 进行普通 $\mathrm{Pb}$ 的校正, 数据处理采用 Ludwig 的 SQUID ${ }^{[50]}$ 和 ISOPLOT/EX (v2.06) ${ }^{[51]}$ 程序. 测试 数据列于表 1 中.

\section{3 分析结果及地质意义}

阴极发光(CL)图像显示(图 4), 样品 09SJH2 具有

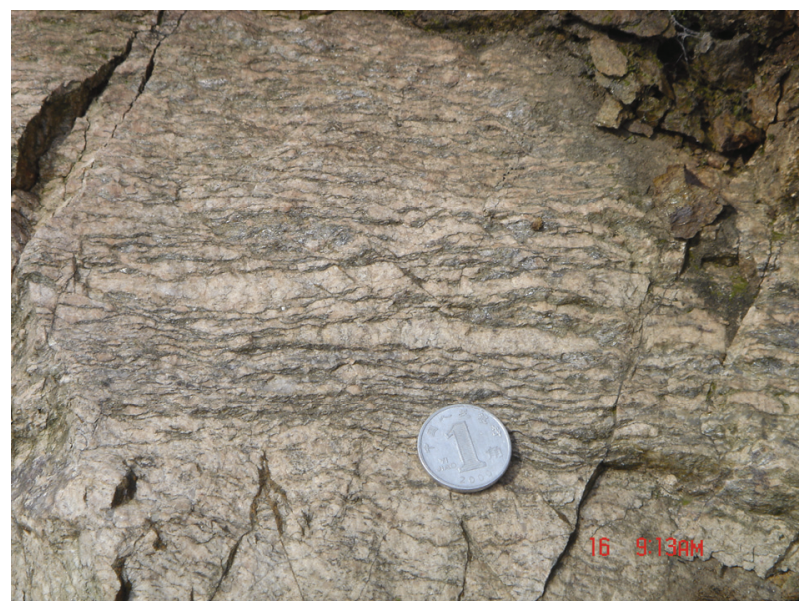

图 2 北淮阳带西段吘湾北部变质花岗岩的野外照片 

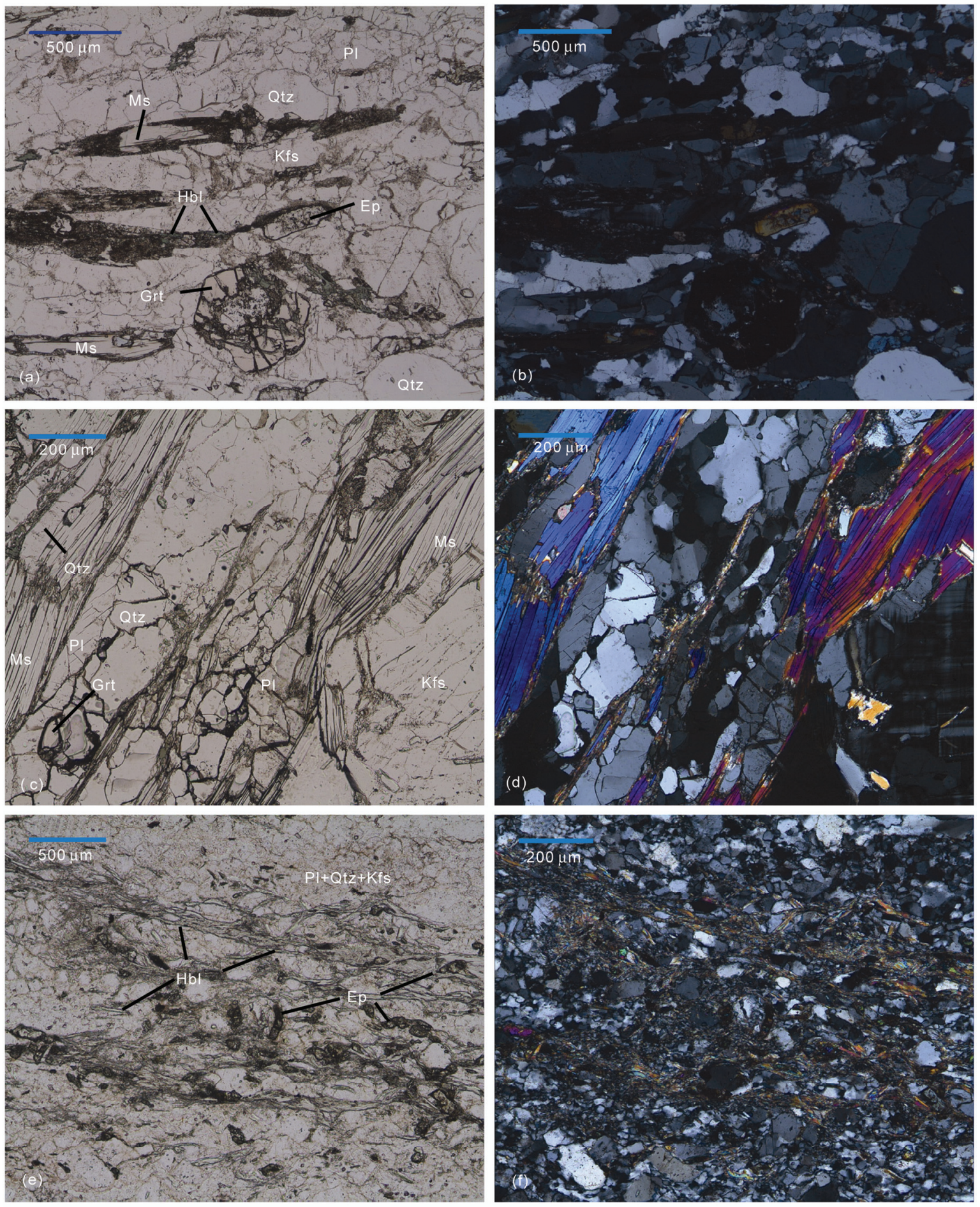

图 3 北淮阳带西段苏家河含石榴变质花岗岩((a) (d)) 和浒湾变质花岗岩 $((\mathbf{e}),(\mathbf{f}))$ 的显微照片

(a), (c)和(e)为单偏光; (b), (d) 和(f)为 (a), (c) 和(e)相对应的正交偏光照片; $\mathrm{Kfs}$, 钾长石; Pl, 斜长石; Qtz, 石英; Ms, 白云母; Grt, 石榴子石; $\mathrm{Hbl}$, 角闪石; Ep，绿帘石

核-边结构, 即发育较好的、具有岩浆结晶环带的核 和非常薄 $(<20 \mu \mathrm{m})$ 的增生边; 样品 $06 \mathrm{HW} 3-1$ 锆石具
有岩浆结晶环带, 为典型的岩浆锆石, 但未发育增生 边. 这些特征明显不同于北大别经过了超高压及多 
表 1 大别山北淮阳带西段浅变质花岗岩锆石 SHRIMP U-Pb 年龄分析结果 ${ }^{\text {a) }}$

\begin{tabular}{|c|c|c|c|c|c|c|c|c|c|c|c|c|c|c|}
\hline 测点号 & $\begin{array}{c}{ }^{206} \mathrm{~Pb}_{\mathrm{c}} \\
(\%)\end{array}$ & $\begin{array}{c}\mathrm{U} / \\
\mathrm{mg} \cdot \mathrm{g}^{-1}\end{array}$ & $\begin{array}{c}\mathrm{Th} \\
/ \mathrm{mg} \cdot \mathrm{g}^{-1}\end{array}$ & $\begin{array}{l}{ }^{232} \mathrm{Th} \\
{ }^{238} \mathrm{U}\end{array}$ & ${ }^{206} \mathrm{~Pb} / \mathrm{mg} \cdot \mathrm{g}^{-1}$ & $\begin{array}{l}{ }^{207} \mathrm{~Pb}^{*} \\
/^{206} \mathrm{~Pb}^{*}\end{array}$ & $\pm \%$ & $\begin{array}{l}{ }^{207} \mathrm{~Pb}^{*} \\
\rho^{235} \mathrm{U}\end{array}$ & $\pm \%$ & $\begin{array}{l}{ }^{206} \mathrm{~Pb}^{*} \\
/^{238} \mathrm{U}\end{array}$ & $\pm \%$ & $\begin{array}{c}{ }^{206} \mathrm{~Pb} /{ }^{238} \mathrm{U} \\
\text { 年龄/Ma }\end{array}$ & $\begin{array}{c}{ }^{207} \mathrm{~Pb} /{ }^{206} \mathrm{~Pb} \\
\text { 年龄 } / \mathrm{Ma}\end{array}$ & $\begin{array}{c}{ }^{208} \mathrm{~Pb} /{ }^{232} \mathrm{Th} \\
\text { 年龄/Ma }\end{array}$ \\
\hline \multicolumn{15}{|l|}{ 09SJH } \\
\hline 1 & 0.56 & 198 & 112 & 0.59 & 20.0 & 0.0638 & 4.4 & 1.028 & 4.5 & 0.1168 & 0.95 & $712 \pm 6$ & $735 \pm 92$ & $696 \pm 26$ \\
\hline 2 & 0.04 & 809 & 410 & 0.52 & 83.6 & 0.0636 & 1.3 & 1.052 & 1.4 & 0.1201 & 0.48 & $731 \pm 3$ & $727 \pm 27$ & $718 \pm 9$ \\
\hline 3 & - & 419 & 369 & 0.91 & 43.6 & 0.0649 & 3.0 & 1.083 & 3.0 & 0.1210 & 0.65 & $737 \pm 5$ & $772 \pm 62$ & $724 \pm 15$ \\
\hline 4 & 0.27 & 267 & 95.9 & 0.37 & 27.7 & 0.0650 & 2.6 & 1.081 & 2.8 & 0.1205 & 0.90 & $734 \pm 6$ & $776 \pm 55$ & $724 \pm 25$ \\
\hline 5 & 0.87 & 174 & 94.4 & 0.56 & 18.3 & 0.0610 & 3.9 & 1.022 & 4.1 & 0.1216 & 1.1 & $740 \pm 8$ & $638 \pm 84$ & $762 \pm 26$ \\
\hline 6 & 0.28 & 263 & 149 & 0.59 & 26.7 & 0.0644 & 3.8 & 1.043 & 3.9 & 0.1175 & 0.82 & $716 \pm 6$ & $754 \pm 81$ & $699 \pm 31$ \\
\hline 7 & 2.07 & 57 & 42.9 & 0.78 & 5.82 & 0.0696 & 12 & 1.120 & 12 & 0.1170 & 1.9 & $713 \pm 13$ & $917 \pm 240$ & $707 \pm 64$ \\
\hline 8 & 0.36 & 372 & 158 & 0.44 & 37.8 & 0.0650 & 2.0 & 1.055 & 2.1 & 0.1178 & 0.69 & $718 \pm 5$ & $774 \pm 43$ & $726 \pm 16$ \\
\hline 9 & 0.31 & 199 & 141 & 0.74 & 20.2 & 0.0614 & 6.6 & 0.992 & 6.6 & 0.1171 & 0.97 & $714 \pm 7$ & $655 \pm 140$ & $671 \pm 24$ \\
\hline 10 & 0.02 & 182 & 129 & 0.73 & 18.7 & 0.0653 & 5.4 & 1.071 & 5.5 & 0.1190 & 1.0 & $725 \pm 7$ & $783 \pm 110$ & $702 \pm 25$ \\
\hline 11 & 0.04 & 318 & 163 & 0.53 & 32.6 & 0.0640 & 1.8 & 1.051 & 2.0 & 0.1191 & 0.74 & $725 \pm 5$ & $743 \pm 39$ & $708 \pm 13$ \\
\hline 12 & 0.84 & 253 & 120 & 0.49 & 25.9 & 0.0599 & 4.4 & 0.975 & 4.4 & 0.1182 & 0.88 & $720 \pm 6$ & $599 \pm 94$ & $717 \pm 32$ \\
\hline \multicolumn{15}{|l|}{ 06HW3-1 } \\
\hline 1 & 1.09 & 195 & 191 & 1.01 & 21.7 & 0.0619 & 3.4 & 1.096 & 3.9 & 0.1284 & 1.8 & $779 \pm 13$ & $671 \pm 74$ & $764 \pm 20$ \\
\hline 2 & 1.21 & 184 & 182 & 1.02 & 19.8 & 0.0636 & 3.8 & 1.086 & 4.0 & 0.1239 & 1.4 & $753 \pm 10$ & $728 \pm 80$ & $762 \pm 19$ \\
\hline 3 & 1.73 & 146 & 204 & 1.45 & 15.7 & 0.0616 & 4.9 & 1.044 & 5.1 & 0.1229 & 1.5 & $748 \pm 10$ & $660 \pm 100$ & $723 \pm 18$ \\
\hline 4 & 1.53 & 134 & 137 & 1.05 & 15.5 & 0.0606 & 4.8 & 1.106 & 5.0 & 0.1324 & 1.5 & $802 \pm 11$ & $625 \pm 100$ & $789 \pm 23$ \\
\hline 5 & 0.83 & 167 & 149 & 0.92 & 18.8 & 0.0611 & 3.1 & 1.094 & 3.4 & 0.1300 & 1.4 & $788 \pm 10$ & $641 \pm 68$ & $797 \pm 19$ \\
\hline 6 & 6.03 & 45 & 52 & 1.19 & 5.02 & 0.0510 & 21 & 0.860 & 21 & 0.1218 & 2.4 & $741 \pm 17$ & $256 \pm 480$ & $680 \pm 63$ \\
\hline 7 & 0.99 & 236 & 158 & 0.69 & 25.3 & 0.0644 & 3.7 & 1.096 & 3.9 & 0.1234 & 1.4 & $750 \pm 10$ & $755 \pm 77$ & $932 \pm 26$ \\
\hline 8 & 3.83 & 58 & 81 & 1.44 & 6.68 & 0.0617 & 12 & 1.100 & 12 & 0.1289 & 2.9 & $782 \pm 21$ & $663 \pm 250$ & $773 \pm 41$ \\
\hline 9 & 2.33 & 116 & 139 & 1.24 & 13.3 & 0.0603 & 7.4 & 1.089 & 7.5 & 0.1310 & 1.5 & $794 \pm 11$ & $614 \pm 160$ & $797 \pm 28$ \\
\hline 10 & 1.92 & 166 & 163 & 1.01 & 18.2 & 0.0590 & 6.0 & 1.017 & 6.2 & 0.1251 & 1.4 & $760 \pm 10$ & $565 \pm 130$ & $726 \pm 26$ \\
\hline 11 & 3.62 & 95 & 142 & 1.53 & 10.4 & 0.0557 & 10 & 0.943 & 10 & 0.1228 & 1.7 & $747 \pm 12$ & $441 \pm 220$ & $701 \pm 28$ \\
\hline 12 & 0.68 & 328 & 97 & 0.30 & 38.7 & 0.0631 & 2.3 & 1.186 & 2.7 & 0.1362 & 1.3 & $823 \pm 10$ & $712 \pm 49$ & $780 \pm 33$ \\
\hline 13 & 2.21 & 131 & 172 & 1.36 & 14.6 & 0.0536 & 7.0 & 0.937 & 7.2 & 0.1267 & 1.6 & $769 \pm 11$ & $356 \pm 160$ & $737 \pm 23$ \\
\hline 14 & 2.69 & 79 & 106 & 1.38 & 8.73 & 0.0592 & 9.8 & 1.020 & 10 & 0.1248 & 2.7 & $758 \pm 20$ & $574 \pm 210$ & $705 \pm 34$ \\
\hline 15 & 2.47 & 91 & 147 & 1.66 & 9.50 & 0.0544 & 8.5 & 0.889 & 8.6 & 0.1186 & 1.7 & $722 \pm 11$ & $387 \pm 190$ & $677 \pm 22$ \\
\hline 16 & 1.17 & 195 & 195 & 1.03 & 20.5 & 0.0625 & 3.6 & 1.046 & 4.0 & 0.1213 & 1.7 & $738 \pm 12$ & $692 \pm 76$ & $725 \pm 19$ \\
\hline
\end{tabular}

a) 误差为 $1 \sigma, \mathrm{Pb}_{\mathrm{c}}$ 和 $\mathrm{Pb}^{*}$ 分别表示普通铅和放射性成因铅; 年龄值用实测的 ${ }^{204} \mathrm{~Pb}$ 值进行普通铅校正

期变质作用的花岗片麻岩中锆石的阴极发光图像 ${ }^{[18]}$, 后者通常发育特征的核-幔-边结构即表现为岩浆锆 石核、超高压变质幔和退变质增生边. 因而从另一方 面证明研究区变质花岗岩可能具有不同于北大别超 高压花岗片麻岩的变质演化过程.

年龄结果(图 5)表明: (1) 样品 09SJH2 中具有岩 浆结晶环带的 12 个锆石核 ${ }^{206} \mathrm{~Pb} /{ }^{238} \mathrm{U}$ 谐和年龄的加权 平均值为 $t=(726 \pm 6) \mathrm{Ma}(\mathrm{MSWD}=2.6)$, 锆石增生边较 薄(小于 $20 \mu \mathrm{m}$ )而不能定年; (2) 样品 06HW3-1 中锆 石有 16 个分析点, 除去 5 个不谐和的测点外, 其余具 有岩浆结晶环带的 11 个锆石 ${ }^{206} \mathrm{~Pb} /{ }^{238} \mathrm{U}$ 谐和年龄的加 权平均值为 $t=(758 \pm 12) \mathrm{Ma}(\mathrm{MSWD}=2.1)$. 因此, 北
淮阳带西段两个浅变质花岗岩的形成时代分别为 (726 \pm 6$)$ 和 $(758 \pm 12) \mathrm{Ma}$ ，类似于北淮阳带东段庐镇关 杂岩的形成时代(720 780 Ma)(见前文所述).

上述定年样品的围岩为原“定远组”变质火山岩 (含石榴子石绿帘云母石英片岩), 而这些变质火山岩 的锆石 SHRIMP U-Pb 年龄 $((464 \pm 7) \mathrm{Ma})^{[20]}$ 及其全岩 的 $\mathrm{Sm}-\mathrm{Nd}$ 和 $\mathrm{Rb}-\mathrm{Sr}$ 等时线年龄分别为 $(446 \pm 23)$ 和 (445 \pm 31$) \mathrm{Ma}^{[34]}$, 指示它们形成于奥陶纪; 这些变质 火山岩地球化学特征指示它们形成于岛弧环境 ${ }^{[34]}$. 而且, 它们与马畈闪长岩的形成时代(锆石 $\mathrm{U}-\mathrm{Pb}$ 年龄 $(463.5 \pm 3.4) \mathrm{Ma}$ 和角闪石 $\mathrm{Ar}-\mathrm{Ar}$ 年龄为 $(462.7 \pm 1.4)$ $\mathrm{Ma}^{[35]}$ 一致。这进一步证明, 北淮阳带西段存在奥陶 

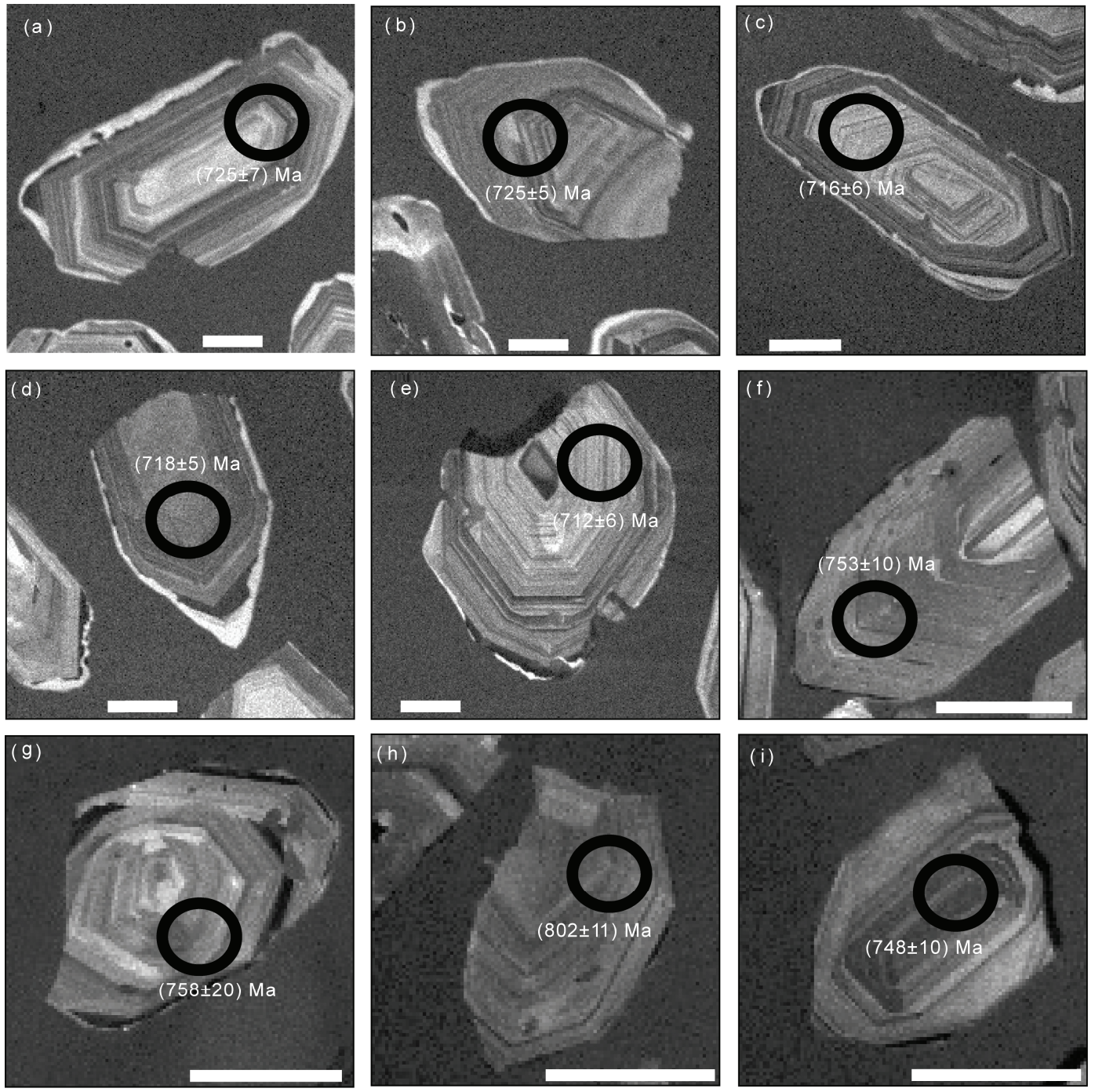

图 4 部分测定锆石的阴极发光图像

(a) (e)和(f) (i) 分别为样品 $09 \mathrm{SJH} 2$ 和 $06 \mathrm{HW} 3-1$ 的阴极发光图像, 比例尺棒为 $50 \mu \mathrm{m}$

纪岩浆弧, 并且可能是华北陆块南缘(北秦岭)古生代 岩浆弧的东延部分 ${ }^{[34,35]}$.

因此，结合刘贻灿等人 ${ }^{[20]}$ 前期在北淮阳带西段 王母观一带发现的形成时代为 $635 \mathrm{Ma}$ 的变质辉长岩, 原“定远组”变质火山岩带中至少包含两类新元古代 浅变质岩片, 即 726 758 Ma 的浅变质花岗岩和 $635 \mathrm{Ma}$ 的变质辉长岩. 这些新元古代浅变质岩的形 成时代与大别山超高压岩石的原岩时代以及华南陆 块北缘湖北随州-束阳等地发育的二期大规模新元古 代中、晚期基性岩墙群和花岗岩的时代(630 640 和 $710 \sim 820 \mathrm{Ma})^{[52]}$ (洪吉安, 2010, 私人通讯)一致, 指示 它们可能有类似的大地构造背景即形成于华南陆块
北缘的裂谷环境. 考虑到北淮阳带西段新元古代浅 变质岩出露于湤湾混杂岩带以北的变质奥陶纪火山 弧之中，该火山弧被认为可与华北南缘北秦岭丹凤 群火山弧对比 ${ }^{[34]}$, 而且, 它与其围岩-变质(绿帘角闪 岩相)奥陶纪岩浆弧火山岩之间为构造接触 ${ }^{[20]}$ 以及二 者分别形成于不同的大地构造背景. 此外, 研究区浅 变质岩石的云母中曾发现有 224 258 Ma 的印支期 $\mathrm{K}-\mathrm{Ar}$ 年龄记录 ${ }^{[53]}$, 而云母的 $\mathrm{K}-\mathrm{Ar}$ 封闭温度较低以及 研究区浅变质岩石为绿帘角闪岩相-绿片岩相 ${ }^{[34,46]}$, 因而它们可能是印支期华南陆块发生深俯冲的初始 阶段被挤离与脱耦的岩片，并在后期构造作用过程 中被推覆到华北南缘古生代浅变质岩系之上. 因此, 

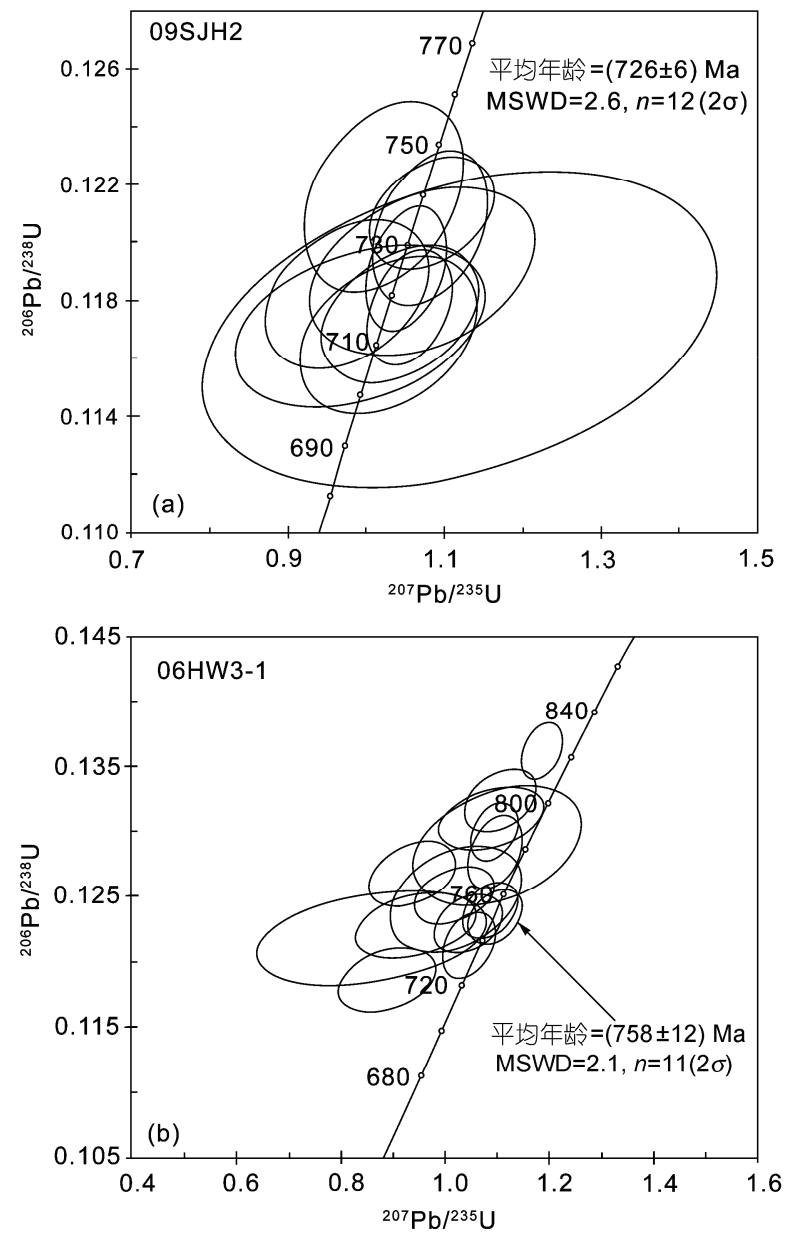

图 5 北淮阳带西段苏家河含石榴变质花岗岩(a)和浒湾变质 花岗岩(b)的锆石 SHRIMP U-Pb 谐和图

北淮阳带西段这些新元古代浅变质岩片的就位机制 可能类似于 Zheng 等人 ${ }^{[28]}$ 在研究大别-苏鲁造山带北 缘浅变质岩时提出的大陆俯冲过程中被动大陆边缘 变形加积楔模型, 而与 Tang 等人 ${ }^{[32]}$ 提出的模式略有 不同. 后者是在印支期华南陆块发生深俯冲的过程 中被挤离、折返, 但随着大陆深俯冲的继续进行和 南、北陆块的汇聚而被推覆于华北陆块南缘变质的岩 石单位之上. 它们的区别是前者是在陆壳俯冲初始 阶段最早被拆离解耦的、变质程度低, 因而没发生变 质锆石增生; 后者被拆离解耦时, 陆壳已俯冲到开始 大规模脱水阶段, 变质程度较高(角闪岩相)并有变质 铅石增生发生, 从而记录有三叠纪变质年龄. 这说明 华南俯冲陆壳在发生榴辉岩相变质前有可能在浅部 不同深度发生了地壳的拆离 ${ }^{[20,28,32,33]}$. 但是, 所述这
些机制与 Zhou 等人 ${ }^{[54]}$ 最近提出的模型的不同之处是: 后者在苏鲁石桥绿片岩相岩石中发现具有华北属性 的 2700 1800 Ma 碎屑锆石并由此认为这些低级变质 岩形成于华北陆块南缘，但随华南陆块的俯冲和华 南与华北陆块碰撞作用的相继发生, 造成华北南缘 石桥等地的低级变质岩以构造岩片的形式逆冲推覆 于苏鲁一带超高压带之上.

综上所述，鉴于北淮阳带西段是研究大别山大 陆俯冲前演化历史的最佳地区 (见前文), 北淮阳带西 段新元古代浅变质岩的野外分布调查以及进一步的 系统岩石学、年代学和地球化学等方面深人研究, 一 方面可以验证目前提出的模式，另一方面必将有助 于完整认识大陆俯冲过程中壳内拆离解耦的发生时 间序列与折返就位机制, 而且, 还有助于理解华南陆 块北缘新元古代中、晚期岩浆活动的特点和形成构造 背景.

\section{4 结论}

(i ) 在北淮阳带西段发现形成时代为 $(726 \pm 6)$ $(758 \pm 12) \mathrm{Ma}$ 的浅变质花岗岩.

(ii ) 北淮阳带西段的新元古代浅变质岩片至少 包括两类岩石：一类是 $635 \mathrm{Ma}$ 的变基性岩, 另一类 是 726 758 Ma 的变质花岗岩. 这些浅变质岩石与大 别山超高压岩石的原岩时代以及华南陆块北缘湖北 随州-杳阳等地发育的二期大规模新元古代中、晚期 基性岩墙群和花岗岩的时代一致，属于华南陆块北 缘的一部分, 这一方面进一步指示华南陆块北缘在 新元古代中、晚期仍处于拉张环境并发育与两期大陆 裂解事件有关的岩石学记录, 另一方面为华南陆块 南沱和古城冰期的结束时间提供了新的制约. 此外, 新发现的新元古代浅变质花岗岩为大别山超高压岩 石的原岩性质及其形成与折返机制等方面研究提供 了新的研究对象.

(iii) 大别山超高压带及北淮阳带中新元古代浅 变质岩石的成因机制可能是：它们是印支期华南陆 块发生深俯冲的初始阶段最早被挤离与脱耦的岩片, 但随大陆深俯冲的继续进行和南、北陆块的汇聚以及 燕山期大别山大规模抬升、剥蚀，一部分呈构造推覆 体或岩片形式产出于超高压带中(如港河绿片岩相岩 石), 另一部分则逆冲推覆于华北陆块南缘变质的岩 石单位之上(如北淮阳带). 


\section{参考文献}

1 Hoffman P F, Kaufman A J, Halverson G P, et al. A Neoproterozoic Snowball Earth. Science, 1998, 281: 1342-1346

2 Hoffman P F. The break-up of Rodinia, birth of Gondwana, true polar wander and the snowball Earth. J African Earth Sci, 1999, 28: 17-33

3 Condon D, Zhu M, Bowring S, et al. U-Pb Ages from the Neoproterozoic Doushantuo Formation, China. Science, 2005, $308: 98$

4 Hoffmann K H, Condon D J, Bowring S A, et al. U-Pb zircon date from the Neoproterozoic Ghaub Formation, Namibia: Constraints on Marinoan glaciation. Geology, 2004, 32: 817-820

5 Zhang $\mathrm{S} \mathrm{H}$, Jiang G Q, Zhang $\mathrm{J} \mathrm{M}$, et al. U-Pb sensitive high-resolution ion microprobe ages from the Doushantuo Formation in south China: Constraints on late Neoproterozoic glaciaiton. Geology, 2005, 33: 473-476

6 Zheng Y F, Wu Y B, Gong B, et al. Tectonic driving of Neoproterozoic glaciations: Evidence from extreme oxygen isotope signature of meteoric water in granite. Earth Planet Sci Lett, 2007, 256: 196-210

7 Zhao Y Y, Zheng Y F. Stable isotope evidence for involvement of deglacial meltwater in Ediacaran carbonates in South China. Chem Geol, 2010, 271: 86-100

8 Macdonald F A, Schmitz M D, Crowley J L, et al. Calibrating the Cryogenian. Science, 2010, 327: 1241-1243

9 Li Z X, Li X H, Kinny P D, et al. Geochronology of Neoproterozoic syn-rift magmatism in the Yangtze Craton, South China and correlations with other continents: Evidence for a mantle superplume that broke up Rodinia. Precambrian Res, 2003, 122: 85-109

10 Zheng Y F, Wu Y B, Chen F K, et al. Zircon U-Pb and oxygen isotope evidence for a large-scale ${ }^{18} \mathrm{O}$ depletion event in igneous rocks during the Neoproterozoic. Geochim Cosmochim Acta, 2004, 68: 4145-4165

11 Zheng Y F, Gong B, Zhao Z F, et al. Zircon U-Pb age and O isotope evidence for Neoproterozoic low- ${ }^{18} \mathrm{O}$ magmatism during supercontinental rifting in South China: Implications for the snowball Earth event. Am J Sci, 2008, 308: 484-516

12 Hoffman P F, Schrag D P. The snowball Earth hypothesis: Testing the limits of global change. Terra Nova, 2002, 14: 129-155

13 Ames L, Zhou G Z, Xiong B C. Geochronology and isotopic character of ultrahigh-pressure metamorphism with implications for the collision of the Sino-Korean and Yangtze cratons, central China. Tectonics, 1996, 15: 472-489

14 Rowley D B, Xue F, Tucker R D, et al. Ages of ultrahigh pressure metamorphism and protolith orthogneisses from the eastern Dabie Shan: $\mathrm{U} / \mathrm{Pb}$ zircon geochronology. Earth Planet Sci Lett, 1997, 151: 191-203

15 Hacker B R, Ratschbacher L, Webb L E, et al. Zircon ages constrain the architecture of the ultrahigh-pressure Qinling-Dabie orogen, China. Earth Planet Sci Lett, 1998, 161: 215-230

16 Zheng Y F, Fu B, Gong B, et al. Stable isotope geochemistry of ultrahigh pressure metamorphic rocks from the Dabie-Sulu orogen in China: Implications for geodynamics and fluid regime. Earth Sci Rev, 2003, 62: 105-161

17 Liu Y C, Li S, Gu X, et al. Ultrahigh-pressure eclogite transformed from mafic granulite in the Dabie orogen, East-central China. J Metamorph Geol, 2007, 25: 975-989

18 Liu Y C, Li S, Xu S. Zircon SHRIMP U-Pb dating for gneiss in northern Dabie high T/P metamorphic zone, central China: Implication for decoupling within subducted continental crust. Lithos, 2007, 96: 170-185

19 Zheng Y F, Wu R X, Wu Y B, et al. Rift melting of juvenile arc-derived crust: Geochemical evidence from Neoproterozoic volcanic and granitic rocks in the Jiangnan Orogen, South China. Precambrian Res, 2008, 163: 351-383

20 刘贻灿, 李曙光, 古晓锋, 等. 北淮阳王母观橄榄辉长岩的锆石 SHRIMP U-Pb 年龄及其地质意义. 科学通报, 2006, 51: 2175一 2180

21 董树文，王小凤，黄德志. 大别山超高压变质带内浅变质岩片的发现及意义. 科学通报, 1996, 41: 815一820

22 周建波，郑永飞，李龙，等.大别-苏鲁超高压变质带内部的浅变质岩. 岩石学报, 2001, 17: 39-48

23 Hacker B R, Ratschbacher L, Webb L, et al. Exhumation of ultrahigh-pressure continental crust in east central China: Late Triassic-Early Jurassic tectonic unroofing. J Geophys Res, 2000, 105: 13339-13364

24 周建波, 郑永飞, 李龙, 等. 扬子板块俯冲的构造加积楔. 地质学报, 2001, 75: 338一 352

25 谢智, 陈江峰, 张巽, 等. 北淮阳新元古代基性侵人岩年代学初步研究. 地球学报, 2002, 23: 517一 520

26 Chen F K, Guo J H, Jiang L L, et al. Provenance of the Beihuaiyang lower-grade metamorphic zone of the Dabie ultrahigh-pressure collisional orogen, China: Evidence from zircon ages. J Asian Earth Sci, 2003, 22: 343-352

27 Wu Y B, Zheng Y F, Zhou J B. Neoproterozoic granitoid in northwest Sulu and its bearing on the North China-South China Block boundary in east China. Geophys Res Lett, 2004, 31: L07616, doi:10.1029/2004GL019785 
28 Zheng Y F, Zhou J B, Wu Y, et al. Low-grade metamorphic rocks in the Dabie-Sulu orogenic belt: A passive-margin accretionary wedge deformed during continent subduction. Int Geol Rev, 2005, 47: 851-871

29 江来利, Wolfgang Siebel, 陈福坤, 等. 大别造山带北部卢镇关杂岩的 U-Pb 锆石年龄. 中国科学 D 辑: 地球科学, 2005, 35: 411一 419

30 Wu Y B, Zheng Y F, Tang J, et al. Zircon U-Pb dating of water-rock interaction during Neoproterozoic rift magmatism in South China. Chem Geol, 2007, 246: 65-86

31 Zhou J B, Wilde S A, Zhao G C, et al. SHRIMP U-Pb zircon dating of the Wulian complex: Defining the boundary between the North and South China Cratons in the Sulu Orogenic Belt, China. Precambrian Res, 2008, 162: 559-576

32 Tang J, Zheng Y F, Wu Y B, et al. Zircon SHRIMP U-Pb dating, C and O isotopes for impure marbles from the Jiaobei terrane in the Sulu orogen: Implication for tectonic affinity. Precambrian Res, 2006, 144: 1-18

33 刘贻灿, 李曙光. 俯冲陆壳内部的拆离和超高压岩石的多板片差异折返: 以大别-苏鲁造山带为例. 科学通报, 2008, 53: 21532165

34 Li S G, Huang F, Nie Y H, et al. Geochemical and geochronological constrains on the suture location between the North and South China Blocks in the Dabie orogen, central China. Phys Chem Earth (A), 2001, 26: 655-672

35 马昌前, 明厚利, 杨坤光. 大别山北麓的奥陶纪岩浆弧: 侵人年代学和地球化学证据. 岩石学报, 2004, 20: 393一 402

36 Okay A I. Petrology of a diamond and coesite-bearing metamorphic terrain: Dabie Shan, China. Eur J Mineral, 1993, 5: 659—675

37 徐树桐, 刘贻灿, 江来利, 等. 大别山造山带的构造几何学和运动学. 合肥: 中国科学技术大学出版社, 2002.1 - 133

38 徐树桐, 刘贻灿, 陈冠宝, 等. 大别山、苏鲁地区榴辉岩中新发现的微粒金刚石. 科学通报, 2003, 48: 1069-1075

39 刘贻灿, 李曙光. 大别山下地壳岩石及其深俯冲. 岩石学报, 2005, 21: 1059-1066

40 Sun W, Williams I S, Li S. Carboniferous and Triassic eclogites in the western Dabie Mountains, east-central China: Evidence for protracted convergence of the North and South China Blocks. J Metamorph Geol, 2002, 20: 873-886

41 Liu X, Jahn B M, Liu D, et al. SHRIMP U-Pb zircon dating of a metagabbro and eclogites from western Dabieshan (Hong'an Block), China, and its tectonic implications. Tectonophysics, 2004, 394: 171-192

42 高山, Qiu Y, 凌文黎, 等. 大别山英山和熊店榴辉岩单颗粒锆石 SHRIMP U-Pb 年代学研究. 地球科学, 2002, 27: 558一 564

43 Fu B, Zheng Y, Touret J L R. Petrological, isotopic and fluid inclusion studies of eclogites from Sujiahe, NW Dabie Shan (China). Chem Geol, 2002,187: 107-128

44 Wu Y, Hanchar J M, Gao S. Age and nature of eclogites in the Huwan shear zone, and the multi-stage evolution of the Qinling-Dabie-Sulu orogen, central China. Earth Planet Sci Lett, 2009, 277: 345-354

45 Cheng H, King R L, Nakamura E. Transitional time of oceanic to continental subduction in the Dabie orogen: Constraints from U-Pb, Lu-Hf, Sm-Nd and Ar-Ar multichronometric dating. Lithos, 2009, 110: 327-342

46 叶伯丹, 简平, 许俊文, 等. 桐柏-大别造山带北坡苏家河地体拼接带及其构成和演化. 武汉: 中国地质大学出版社, 1993.1 - 81

47 宋彪, 张玉海, 万渝生, 等. 锆石 SHRIMP 样品靶制作、年龄测定及有关现象讨论. 地质论评, 2002, 48(增刊): 26一 30

48 Williams I S, Claesson S. Isotopic evidence for the Precambrian provenance and Caledonian metamorphism of high grade paragneisses from the Seve Nappes, Scandianavian Caledonides: II ion microprobe zircon U-Th-Pb. Contrib Mineral Petrol, 1987, 97: 205-217

49 Compston W, Williams I S, Kirschvinck J L, et al. Zircon U-Pb ages for the Early Cambrian time-scale. J Geol Soc, 1992, 149: 171-184

50 Ludwig K R. Squid 1.02: A user manual, 2001. 1-19

51 Ludwig K R. User's manual for Isotope/EX Version 2.06, 1999. 1-47

52 陆松年, 李怀坤, 陈志宏, 等. 秦岭中-新元古代地质演化及对 Rodinia 超级大陆事件的响应. 北京: 地质出版社, 2003. 1一 194

53 陈江峰, 董树文, 邓衍尧, 等. 大别造山带钾氩年龄解释一一差异抬升的地块. 地质论评, 1993, 39: 17一22

54 Zhou J B, Wilde S A, Zhao G C, et al. Detrital zircon U-Pb dating of low-grade metamorphic rocks in the Sulu UHP belt: Evidence for overthrusting of the North China Craton onto the South China Craton during continental subduction. J Geol Soc, 2008, 165: 423-433 